LIMA, F. J. (2020)

0 fenômeno religioso na pós-modernidade

DOl: $10.31416 /$ rsd v. v8i2. 58

\title{
O fenômeno religioso na pós-modernidade \\ o fenômeno religioso na pós-modernidade
}

\section{LIMA, Francisco José de Lima.}

Licenciado em Filosofia pela FAFIC, Faculdade de Ciência e Letras de Cajazeiras- PB. Bacharel em Teologia pela Faculdade Católica de Fortaleza-CE. Mestre em Ciências do Matrimônio e da Família pelo Instituto João Paulo II de Valencia- ESP. CEP: 56200-000. Telefone (87) 98122-2215/98122-3778. E-mail:pintopetrolina@yahoo.com.br

RESUMO: Este artigo analisa como na pós-modernidade a religião possui características muito particulares. Na Modernidade, muitos filósofos chegaram a profetizar o fim da religião; partia-se do pressuposto de que com o advento da ciência e da técnica o homem seria capaz de responder e solucionar os grandes problemas econômicos, sociais e existenciais. A vivência religiosa seria descartável por agora, o ser humano seria capaz de por ele mesmo encontrar a justificação da sua existência e sobretudo, a felicidade. Esta profecia não se realizou justamente porque a pósmodernidade é marcada fortemente por uma efervescência religiosa. Este retorno à religião se caracteriza, dentre outras coisas, por um acentuado pluralismo de concepções religiosas e sobretudo por uma vivência individualista da religião. Estamos, pois, diante de algo tremendamente novo.

Palavras-chave: pós-modernidade, fenômeno religioso, secularismo, individualismo, irracionalismo.

\section{The religious phenomenon in postmodernity}

ABSTRACT: This article analyzes how in postmodernity religion has very particular characteristics. In modernity many philosophers came to prophesy the end of religion, it was assumed that with the advent of science and technology, man would be able to answer and solve problems. major economic, social and existential problems. The religious experience would be disposable for now the human being would be able to find the justification for his existence and, above all, happiness. This prophecy was not realized precisely because postmodernity is strongly marked by a strong religious effervescence. This return to religion is characterized, among other things, by an accentuated pluralism of religious concepts and, above all, by an individualistic experience of religion. People want to experience the Sacred, but that does not mean they are linked to any institution. We are therefore facing something tremendously new.

Keywords: postmodernity, religious phenomenon, secularism, individualism, irrationalism.

\section{Introdução}

O homem é filho do seu tempo. Portanto, para entender o contexto humano e social em que vivemos, é uma tarefa essencial conhecer os recursos que caracterizam esse contexto específico. De fato, seria uma injustiça, por exemplo, julgar a Idade Média com os óculos de nossa mentalidade atual. Qualquer estudante sério sabe que é contra a objetividade fazer julgamentos de valor sobre uma sociedade sem se colocar de uma certa maneira no mundo político e social dessa mesma sociedade. Do mesmo modo, para interpretar bem nossa atual conjuntura histórica chamada pósmodernidade, é necessário entender o que entendemos pela pós-modernidade e suas características.

0 documento de Aparecida nos diz que "hoje estamos vivendo não apenas um tempo de mudança, mas estamos testemunhando uma mudança de tempo" (DOCUMENTO DE APARECIDA, 2007, p. 44). Em outras palavras, não é uma mudança em nenhum setor da sociedade, mas uma verdadeira revolução que afeta toda a realidade. 
LIMA, F. J. (2020)

O fenômeno religioso na pós-modernidade

Neste artigo, abordaremos de uma maneira particular em relação à forma como o fenômeno religioso é apresentado na pós-modernidade. A religião não é eliminada com o processo de secularização como Augusto Comte ou Marx havia profetizado, entre outros. Na pós-modernidade, ela simplesmente se veste de novas formas e contornos, se reinterpreta e se ressignifica, ressurge e se espalha. Mesmo sem ter o papel de liderança que exerceu no período antigo e medieval, a religião continua a desempenhar um papel importante na pós-modernidade, estando presente em todas as áreas do desenvolvimento humano, embora de maneira velada.

\section{0 que é a pós-modernidade?}

A crise da modernidade, segundo Hannah Arendt e a partir de uma teoria política, foi resolvida e termina com totalitarismo que, pelo menos até meados do século XX, dominam a Europa: Franco, Mussolini, Hitler. "Los totalitarismos han constituido un fenómeno que no se podrá soslayar siempre que se quiera hacer una caracterización de nuestro siglo. Sus orígenes, son el antisemitismo y el imperialismo" (HANNAH ARENDT,1998, p.3). Entende-se o termo Modernidade em seu sentido historiográfico, já que o período que parte de outra crise, a do mundo medieval, começa com o surgimento da subjetividade cartesiana, no século XVII, e a objetividade da ciência físico-matemática termina com o ciclo das grandes guerras europeias de 1914 e 1945.

Segundo alguns autores, o pós-modernismo é a continuação da modernidade; outros, porém, discordam dessa perspectiva, entendem-na como uma ruptura com a modernidade e, portanto, com características peculiares. 0 contexto atual em que nos encontramos recebe nomes diferentes, como "modernidade", “modernidade tardia”, “hipermodernidade”, “pós-modernidade”, entre muitas outras, e apresenta transformações consideráveis e significativas.

O slogan pós-moderno surge com o filósofo francês Jean-François Lyotard, de seu trabalho "La condition postmoderne". Para ele, "a pós-modernidade é perceptível graças ao processo de transformações que ocorreu principalmente nas artes, na ciência e na moral, causando o declínio das meta-histórias da modernidade" (LYOTARD, 1987, p.4). Nesse caso, a pós-modernidade é caracterizada pelo colapso de explicações absolutas sobre a realidade, que tendem a generalizar. Simplificando o máximo possível, a descrença em relação às meta-histórias é pós-moderna. Este é sem dúvida um efeito do progresso das ciências; mas esse progresso, por sua vez, o pressupõe. 0 desuso do dispositivo meta-narrativo de legitimação corresponde especialmente à crise da filosofia metafísica.

Um dos impactos mais profundos dessa mudança de época é, sem dúvida, o que afeta a religião. Se, no lluminismo, a razão humana começa a ocupar o centro do palco e se torna o princípio fundamental que governa a vida humana e permanece como um cânon indiscutível da verdade, agora a mudança é configurada de maneira diferente. A crise da modernidade dará origem a um novo estado 
LIMA, F. J. (2020)

O fenômeno religioso na pós-modernidade

de coisas que o conhecimento humano ainda está longe de ter assimilado definitivamente. E é no século XX que esse novo processo é apresentado com mais clareza.

É muito importante considerar que as crises e seu verdadeiro entendimento são fundamentais para que possamos oferecer respostas adequadas à realidade. A palavra crise vem do idioma grego кpíøı, "sentença", "resultado de um julgamento", "momento decisivo", "seleção", "decisão" (segundo Tucídides), mas também "disputa" ou "reclamação" (segundo Platão) e padrão, o que significa que deriva critérios ("significa formar um julgamento", mas também "capacidade de discernir") e crítico ("apto a julgar", "crucial", "decisivo", bem como sobre a arte de fazer julgamentos) (BAUMAN y BORDONI, 2014, p.7).

A religião, como uma dimensão essencial do homem, sofre as consequências da nova visão de mundo que a modernidade apresenta. Para que algo seja considerado legítimo na modernidade, precisa passar pela compreensão, pelo processo da razão que constitui o ser pensante. 0 ser humano e não Deus, agora se torna o centro do universo. Os conceitos de "secularização" e "progresso" acabam se sobrepondo.

O cristianismo histórico, a religião majoritária no Ocidente, logo verá como fenômenos como o teísmo, ateísmo e agnosticismo surgem a partir de si. Os crentes pareciam não ter escolha senão rejeitar o mundo moderno ou dialogar com o pensamento iluminado. Infelizmente, a Igreja passou muito tempo com medo, fechada ao diálogo com a modernidade.

No entanto, quando a crise surge, a razão iluminada, poderosa e soberana, questionou todo o sistema de entendimento que anteriormente prevalecia. De fato, nossa era não se entende mais como "o império da razão", participa da fragmentação das grandes histórias e utopias e é forçada a repensar todos os conceitos que anteriormente the deram apoio teórico. A própria dificuldade em nomear o período pelo qual passamos mostra sua complexidade. "Modernidade em crise", "modernidade tardia”, “hipermodernidade”, “modernidade líquida”, “pós-modernidade”, a verdade é que nossa era enfrenta e enfrenta a crise de seu modelo.

No entanto, embora no pós-modernismo não seja mais considerado o primado ou império da razão, isso não significa que desapareceu. A pós-modernidade combina dois aspectos muito fortes da vida: a racionalidade e o sentimental. A influência da razão faz tudo parecer previsível, tudo deve estar sobre o controle da racionalidade.

Além disso, a vida pós-moderna é marcada por uma grande convulsão que envolve toda a pessoa: preocupa, com o trabalho, tantas atividades que o ser humano perdeu a capacidade de contemplar a realidade. A sociedade se tornou uma sociedade de operação, transformação, consumo, etc.

Tudo o que era sólido desaparece no ar, tudo o que era seguro é questionado, sacudindo a imagem do ser humano como sujeito absoluto. Um sentimento de desânimo, desconfiança prevalece. A razão não responde mais às grandes questões do ser humano. A cultura individual se torna a cultura que cada indivíduo constrói para si e deixa de ser a sociedade à qual o indivíduo pertence. Há uma rejeição da comunidade e da tradição

A cultura está em crise e a mídia contribui para isso através do excesso de informações, o mundo real é substituído por um mundo virtual. O consumismo e a cultura da imagem são incentivados. 
LIMA, F. J. (2020)

O fenômeno religioso na pós-modernidade

O lema que melhor caracteriza o período em que vivemos pode ser expresso como "o ser humano é o que ele consome e quanto mais ele consome, mais será feliz".

Século sem Deus, onde até as divindades são efêmeras, passageiras e identificadas com objetos de consumo, o século XX constitui o nível mais alto do processo de modernidade. Ao resgatar o transcendente, ele o fragmenta diante do ser humano e o apresenta sem rosto, sem identidade, sem absolutos. As experiências religiosas estão se multiplicando novamente, embora a racionalidade moderna pareça tê-las banido. Mas sua configuração não consiste mais no relacionamento com um Deus pessoal e absoluto, mas no consumo excessivo. Vemos então que na modernidade o mundo deve ser entendido dentro dos limites da pura razão, sem tentar transcender os fatos.

Mas, para eliminar Deus como a referência das sociedades, o homem moderno começa a procurar algo que ocupa o lugar que foi deixado vazio. Na pós-modernidade, ela se volta para Deus como um ponto de referência, mas de uma perspectiva diferente, na qual vários ídolos e fetiches compartilham um papel de liderança com o ser humano. A perspectiva das novas referências é individual, ou seja, cada um escolhe onde, quando e por que seguir um caminho religioso, de acordo com seus desejos e necessidades.

A era da modernidade sólida chegou ao fim. Por que sólido? Porque os sólidos, diferentemente dos líquidos, mantêm sua forma e persistem com o tempo: eles duram. Em vez disso, os líquidos não têm forma e se transformam constantemente: fluem. É por isso que a metáfora da liquidez é adequada para apreender a natureza da atual fase da modernidade. A dissolução de sólidos é a característica permanente dessa fase. Os sólidos que estão derretendo agora, o momento da modernidade líquida, são os elos entre escolhas individuais e ações coletivas. É o momento de desregulamentação, flexibilidade e liberalização de todos os mercados. Não há diretrizes estáveis ou predeterminadas nesta versão privatizada da modernidade. $\mathrm{E}$ quando o público não existe mais como sólido, o peso da construção das diretrizes e a responsabilidade pelo fracasso caem total e fatalmente nos ombros do indivíduo.

A pós-modernidade analisa todos os fenômenos, sobre um único movimento em si, uma lógica cultural que valoriza o relativismo e a indiferença, um conjunto de processos intelectuais flutuantes e indeterminados, uma configuração de características sociais que significariam a erupção de um movimento da descontinuidade da condição moderna: mudanças nos sistemas de produção e crise do trabalho, eclipse da historicidade, crise do individualismo e onipresença da cultura de massa narcísica.

Em linhas gerais, o pós-modernismo supõe uma crise generalizada com tons dos mais variados. Caracteriza-se pela predominância do pensamento fraco e uma virada epistemológica devido ao desencantamento da razão, que não é mais capaz de dizer o que é a realidade, nem de oferecer fundamentos e princípios claros e incontestáveis. Prevalência de contingência provisória e provisória. Surge uma nova sensibilidade que prefere o particular, dispersão, especialização e fragmentação. Do ponto de vista psicológico, a pós-modernidade é caracterizada por uma perda de sentido, vivida como um vazio existencial, que muitas vezes leva a fugir em direção a drogas, consumismo e hedonismo. 
LIMA, F. J. (2020)

O fenômeno religioso na pós-modernidade

Conceituamos e descrevemos em características muito gerais o complexo mundo pós-moderno; na próxima seção, focaremos no fenômeno religioso e como ele é apresentado na sociedade pósmoderna.

\section{Características da religião na pós-modernidade}

Em meados do século XIX, o fim do fenômeno religioso começou a ser previsto pela compreensão da religião em oposição à ciência, mas já era no final do século XIX que parecia de alguma forma destruído ou pelo menos amplamente danificado por aqueles que haviam, eles foram nomeados por Ricoeur como os mestres da suspeita: Marx, Nietsche e Freud. A chegada da ciência e a supremacia da razão (baluartes da modernidade) como verdade acabariam com a religião. Hoje, porém, podemos dizer que não apenas eles não terminaram, é algo em ascensão e, portanto, um campo de conhecimento interessante e desafiador para o cientista social.

Assim, se os binômios "sociedade tradicional - religião", "sociedade moderna, secularização" são aceitos, a sociedade pós-moderna supõe um retorno a essas abordagens quando se fala em “dessecularização", não assumindo o retorno ao sagrado nem uma fuga do em si, mas uma posição equidistante entre o secular e o religioso que coloca o indivíduo pós-moderno em um estado contínuo de incerteza e que o leva a buscar estratégias para tirá-lo desse estado desconfortável. Diante dessa abordagem, estão os autores que falam de "religião à la carte" ou "mercado religioso", em que existem formas relaxadas de religião que satisfazem o indivíduo pós-moderno em comparação com outros movimentos caracterizados pela rigidez de suas abordagens e que eles anulam esse estado de dúvida1.

Abordar o fenômeno religioso no pós-modernismo está enfrentando uma questão complexa, que se torna mais complexa à medida que nos concentramos nos aspectos mais subjetivos dessa nova religiosidade. Diante da enorme diversidade verificada no atual fenômeno religioso e das constantes transformações observadas em todos os seus aspectos, uma vez que ocorre uma troca quase constante de ideias, ritos, símbolos e doutrinas, levantadas de um lado para o outro. 0 outro descasca pela metade, ou isso torna quase impossível dizer quais elementos pertencem ou não a certos grupos religiosos. Ou que seja verificado como uma marca do fenômeno e diversidade, heterogeneidade ou misticismo, sentimentalismo, emocionalismo, ecletismo ou hibridismo religioso ou pragmatismo (como coisas valem enquanto funcionam).

Quando falamos de fenômeno religioso na pós-modernidade, precisamos ter em mente que estamos tratando com uma realidade absolutamente diferente de tudo que já se viu até o momento em termos de experiência com o sagrado.

Alguns anos atrás, a sociedade acreditava que a religião e Deus desapareceriam do mundo. A teoria da secularização garantiu que os religiosos fossem substituídos pela modernidade e pela ciência, e o campo foi aberto para uma cultura pós-cristã e pós-teísta. A teologia da morte de Deus foi dada como um fato certo e era preciso se acostumar a viver sem Deus. No final do século 20, no entanto, houve um reavivamento dos religiosos. Isso levou teóricos como Cox Harvey que ressuscitaram o desaparecimento de Deus em seu famoso livro A Cidade Secular, a repensar seus pensamentos e falar 
LIMA, F. J. (2020)

O fenômeno religioso na pós-modernidade

sobre "um renascimento do espiritual em sua obra Fogo do Céu" (COX HARVEY,1985). A crise na teoria da secularização é verificada e outros marcos interpretativos sobre o renascimento, permanência e ascensão do fenômeno religioso começam a ser delineados. A religião está de volta à moda e há uma revanche de Deus.

\subsection{Secularização, Secularismo e Secularidade}

É muito importante entender a distinção entre essas três palavras secularismo, secularidade, secularização, as três derivadas de "saeculum", século ou mundo, não significam a mesma coisa. Em geral, podemos dizer que o processo de secularização na Europa pode ser descrito como uma dessacralização do mundo, como uma emancipação da realidade cultural dos controles religiosos e do domínio da religião cristã, exercida na antiguidade e na Idade Média. O resultado desse longo processo é um mundo à sua disposição e sob o governo do ser humano, um mundo autônomo, um campo para sua livre investigação, criação e planejamento.

Secularização não é o mesmo que secularismo. 0 que é, então, o secularismo? Por secularismo, entendemos uma concepção do mundo sem nenhuma referência a Dio. Uma concepção do mundo que não reconhece nada real que não seja o mesmo mundo. Uma concepção ou visão da vida humana, à qual toda intervenção de Deus nela é absolutamente estranha.

O secularismo nega a existência e até o significado de toda a realidade que não pode ser especificada ou medida com os métodos das ciências naturais; e, portanto, vai mais longe, na negação de Deus, do que um puro racionalismo ou naturalismo que poderia admitir a existência de Deus e sua operação no mundo, pelo uso da razão natural.

O secularismo transforma os processos históricos da secularização em ideologia antirreligiosa. A secularização é um processo cultural e histórico complexo. 0 secularismo é uma ideologia exclusiva e totalitária. A secularização dá à religião uma oportunidade. Secularismo nenhum. A secularização supõe uma grande liberdade individual em relação à religião, um ambiente de respeito e tolerância.

Portanto, o secularismo implica uma total ausência de Deus no horizonte da vida humana, seja por negação expressa e teórica de sua existência, seja por sua precisão mental. Portanto, o secularismo é ateísmo e, portanto, incompatível com a fé cristã. Mas secularismo não é secularidade; pelo menos não é secularidade saudável. 0 que é, então, secularidade?

É, bem, a realidade do século ou mundo com tudo o que encerra no conjunto de seres que o compõem e considerado realmente diferente de seu autor, como por necessidade deve ser; Bem, e principalmente, a atitude do homem que conhece e aprecia objetivamente essa realidade e, portanto, sua natureza, suas energias polivalentes, seus fins, suas conexões com o Ser supremo que chamamos de Deus, e trabalha de acordo com ele. E do mesmo mundo o comportamento adequado.

Secularidade significa a autonomia legítima do mundo em suas várias dimensões. 0 Concílio Vaticano Segundo define em que consiste essa justa autonomia da ordem temporal:

Se por autonomia da realidade se entende que as coisas criadas e a própria sociedade desfrutam de suas próprias leis e valores, que o homem deve descobrir, empregar e ordenar pouco a pouco, essa demanda por autonomia é absolutamente legítima. Não é apenas que os homens de nosso 
LIMA, F. J. (2020)

O fenômeno religioso na pós-modernidade

tempo exigem isso com urgência. Também responde à vontade do Criador. Pois, pela própria natureza da criação, todas as coisas são dotadas de sua própria consistência, verdade e bondade e de sua própria ordem regulada, que o homem deve respeitar com o reconhecimento da metodologia particular de cada ciência ou arte. Por esse motivo, a pesquisa metódica em todos os campos do conhecimento, se realizada de maneira autenticamente científica e de acordo com normas morais, nunca será realmente contrária à fé, porque realidades profanas e de fé têm origem em o mesmo Deus.

Mas se a autonomia do temporal significa que a realidade criada é independente de Deus e que os homens podem usá-la sem referência ao Criador, não há crente de quem a falsidade envolvida em tais palavras esteja oculta. A criatura sem o Criador desaparece. Além disso, aqueles que acreditam em Deus, qualquer que seja sua religião, sempre ouvem a manifestação da voz de Deus na linguagem da criação. Além disso, esquecendo Deus, a própria criatura é obscurecida.

E assim como um processo desordenado de secularização termina em uma pura antropologia desconectada de Deus, em uma negação de Deus ou deificação do homem (do século, cujo elemento principal é), e na morte de Deus ou no desaparecimento de Deus da vida humana, porque se recusa expressa ou teoricamente ou porque é dispensado; assim, o processo correto de secularização para na secularidade legítima e saudável que consiste, no julgamento exato e objetivo, das realidades terrestres.

Portanto, essa secularidade autêntica e cristã coloca as coisas em seu argumento: afirma o valor do mundo e também a maior dignidade, suprema dignidade de Deus, seu Criador e Redentor; e, consequentemente, a ordenação e sujeição do homem a Deus, em seu ser e em seu comportamento, conforme exigido pela razão natural e pela fé cristã.

Secularização é o movimento ou processo para conhecer e estabelecer no indivíduo e na sociedade a secularidade que acabamos de descrever; e à secularidade saudável, não apenas compatível com a nossa fé católica, mas exigida por ela e ao maligno que a nega. Naturalmente, cristãos e até homens justos que não conheciam a Cristo, mas respeitavam a lei natural, teriam que rejeitar qualquer processo secularizante que buscasse uma secularidade ideal que exclua Deus da mente e da vida; e só aceitariam aquele que aspirasse à secularidade saudável e desenvolvesse o devido respeito pelas exigências da verdade natural religiosa e cristã.

0 mundo fala de Deus. A falsa secularização é realmente uma verdadeira idolatria. A idolatria consiste em fechar o mundo em si mesmo e não apreender sua autonomia como autonomia criada. A teologia cristã da encarnação, nesse sentido, significa e confirma tanto a dignidade do mundo quanto sua diferença com Deus. A ordem criada por Ele mesmo Deve-se dizer que o mundo não é Deus, mas também não é um poder hostil a Deus. Deus é ao mesmo tempo transcendente e imanente. Somente porque Deus é absolutamente transcendente em relação ao mundo, ele também pode ser insuperavelmente imanente ao mundo. Deus quando no mundo sem transgredir.

As teologias da secularização são parabenizadas pelo fato de que, sob o fogo das críticas ao ateísmo moderno, o cristão é obrigado a entrar na idade adulta da fé, isto é, de um mundo sem Deus. Agora, a religião não parece ter desaparecido deste mundo contemporâneo supostamente ateísta. Ainda é habitado por poderes mágicos e reativa, às vezes sem saber, práticas puramente pagãs. 
LIMA, F. J. (2020)

O fenômeno religioso na pós-modernidade

Somente através de um relacionamento dialético entre fé e secularização é que ambos podem ser salvaguardados. A fé ajuda que o mundo não seja idolatrado como um "deus". Por outro lado, apenas a secularização impede uma experiência de fé que rejeita o mundo em sua justa ordem e autonomia.

\subsection{Uma vivência individualista da religião}

$\mathrm{O}$ individualismo pós-moderno e globalizado favorece um estilo de vida que enfraquece $\mathrm{O}$ desenvolvimento e a estabilidade dos laços entre as pessoas e desnatura os laços familiares. A ação pastoral deve mostrar ainda melhor que o relacionamento com nosso Pai exige e incentiva uma comunhão que cura, promove e fortalece os laços interpessoais.

Nas sociedades secularizadas, a experiência religiosa tem de a limitar-se ao privado, ao elegível e ao opinativo. A oferta religiosa é confrontada com a consciência secularizada do sujeito, que se sente totalmente livre para selecionar o que the interessa sobre religião, guiado pelos princípios de eficácia e pragmatismo. "Isso funciona para mim, isso não funciona para mim." Essa afirmação da subjetividade individual na ordem espiritual se manifesta no desenvolvimento de uma prática religiosa à la carte, regulada pelas necessidades pessoais dos fiéis. Existe um verdadeiro sincretismo religioso.

A religiosidade individual se afasta do modelo tradicional e temático. Portanto, proliferam os sincretismos que dissolvem assim a coerência doutrinária das ofertas das Igrejas.

Enquanto na modernidade parecia que tudo apontava para um mundo sem Deus e sem a perspectiva de religiosidade, na pós-modernidade há um retorno ao transcendente. Há um desejo crescente de experiências e práticas religiosas. Uma busca incessante pelo sagrado, sem que isso implique em ouvir qualquer autoridade ou teólogos. Trata-se de procurar algo que chegue ao coração humano e faça você se sentir amado.

Nesse contexto, novas experiências religiosas nascem e se espalham, gerando movimentos, grupos e diferentes associações. Nesses ambientes religiosos, pessoas separadas de instituições históricas sentem-se livres e abertas à experiência do sagrado. Como sabemos na Modernidade, muitos profetizarão o desaparecimento da religião como Augusto Comte, Marx entre outros. No entanto, no pós-modernismo, a religião ocupa um lugar muito importante.

A modernidade queria reduzir a religião aos limites da pura razão. 0 homem se considerava apenas em sua dimensão racional esquecendo a totalidade do humano. $O$ ato de fé foi entendido como aceitação meramente intelectual de um conjunto de doutrinas e teorias religiosas. Pascal, já no século XVIII, havia protestado contra esse racionalismo presente na prática religiosa católica e protestante. Este filósofo critica as provas tradicionais da existência de Deus e afirma que é o coração que Deus experimenta e não apenas a razão.

Na pós-modernidade predomina a primazia da experiência, embora muitas vezes marcada por irracionalismo, sentimentalismo, emocionalismo. O Deus procurado e encontrado nessa nova chave é revelado através da experiência. Mais do que ouvir sobre Deus, o que as pessoas buscam é experimentar Deus. 
LIMA, F. J. (2020)

O fenômeno religioso na pós-modernidade

Apesar dos avanços científicos, novas descobertas não ajudaram os seres humanos a entender a causa ou a razão de sua existência. A ciência falhou em saciar o desejo de Deus no coração humano. Esta busca não é agora sobre religião, mas uma espiritualidade que oferece um caminho para a experiência, algo que dá sentido à vida. A postura deste homem pós-moderno causa espanto e perplexidade nas estruturas eclesiais. Bem, se, por um lado, esse desejo de experiência é um fator positivo para levar o crente a retornar a Deus e desenvolver uma fé mais firme na vida e na vida cotidiana, essa experiência procurada e desejada é, na maioria das vezes, desassociados da norma moral, da verdade dogmática e do pertencimento institucional.

\subsection{Relativismo religioso}

A sociedade moderna é marcada pela crença na verdade absoluta e universal, enquanto o pósmodernismo é marcado por questionar essas verdades e acreditar que não existem valores absolutos. Ou seja, tudo é relativo, não há absolutos de qualquer natureza.

Não podemos falar de religiosidade no contexto pós-moderno dentro de uma visão absoluta, uma vez que uma das características da pós-modernidade é a ausência de absolutos. Entendemos, portanto, que todas as verdades sobre o fenômeno encontram seu limite na própria ideia de relatividade: os fenômenos são e não são ao mesmo tempo, liquidez e volatilidade também são um sinal de pós-modernidade e se refletem da mesma maneira na religião.

Em uma atmosfera de relativismo, as pessoas tendem a construir um universo simbólico a partir de várias ofertas de todos os tipos que ocorrem na sociedade, guiadas pelo imediatismo ou pelo desejo de sensações, e também pela busca de fundamento e significado, pelo desejo de segurança e esperança. Vivemos em uma sociedade de hiperconsumo, excitações e sensações são vendidas.

\subsection{Fé sentimentalista e irracionalista}

Segundo Blaise Pascal, "a fé é um dom que é acolhido pela experiência subjetiva que mesmo sem entender o acolhe movido pelas certezas do coração" (PASCAL, APUD, REALE-ANTISERI, 2005,182). A fé constitui-se, pois, numa profunda experiência de Deus, que é capaz de transformar e renovar o indivíduo mostrando-lhe que ele não se reduz à pura razão, mas que além disso, é dotado de uma dimensão transcendental. É muito importante sublinhar que, para Pascal, a palavra "coração" não designa o irracional o sentimental, mas a dimensão profunda da subjetividade pessoal.

Na religião pós-moderna, pelo contrário, governa a ditadura de emoções e sentimentos. 0 critério da verdade da experiência religiosa são os sentimentos. A fé é uma emoção simples do coração. Sem dúvida, o crente sente sua fé, experimenta e desfruta, mais grave um erro reducionista ou "sentimentalismo". A fé implica a totalidade do homem, incluindo sua afetividade, emoções e sentimentos. No entanto, a fé não é uma experiência que depende de sentimentos: há momentos em que acreditamos que não sentimos grandes emoções, mas isso não significa que perdemos a fé. Acreditar é uma atitude responsável e racional. 
LIMA, F. J. (2020)

O fenômeno religioso na pós-modernidade

$\mathrm{Na}$ pós-modernidade, o homo sapiens foi substituído pelo homo sentimentalis. O homo sentimentalis não é simplesmente o homem que sente, mas o homem que valoriza o sentimento acima da razão. A tirania da razão foi seguida por uma explosão de sensibilidade e subjetividade. Maria clara Bingemer $(2017,19)$, observa que o Deus buscaddo e encontrado desde esta nova chave de compreensão se revela através da experiencia y, sobretudo, através do sentimento da sua presença. Através do sentimento se pode entrar em comunhão com Deus.

Alinhados a essas transformações culturais pós-modernas, alguns filósofos, abandonando a busca da verdade por si mesmos, adotaram como único objetivo alcançar a certeza subjetiva ou a utilidade prática. A partir disso, segue-se como consequência a ofuscação da dignidade autêntica da razão, que não é mais capaz de conhecer o verdadeiro e buscar o absoluto. Sem uma razão aberta ao mistério, a própria experiência da fé pode assumir formas fundamentalistas e irracionais.

Na pós-modernidade, então, há uma separação progressiva entre fé e razão filosófica e isso afeta fortemente o conteúdo da verdadeira experiência da fé. Por essa razão, João Paulo II enfatiza: "o relacionamento atual entre fé e razão exige um esforço cuidadoso de discernimento, uma vez que fé e razão foram empobrecidas e enfraquecidas uma antes da outra" (JOÃO PAULO II, 1998, p.48) A razão, privada da contribuição do Apocalipse, percorreu estradas secundárias que correm o risco de fazê-lo perder de vista seu objetivo final. A fé, privada da razão, sublinhou sentimentos e experiências, correndo o risco de deixar de ser uma proposta universal. É ilusório pensar que a fé, diante de uma razão fraca, tem uma maior incisividade; pelo contrário, corre o sério risco de ser reduzido a mito ou superstição. Do mesmo modo, uma razão que não tem diante de si uma fé adulta não é motivada a direcionar seu olhar para a novidade e a radicalidade do ser.

\subsection{Mercantilização da Religião}

Segundo Jung Mo Sung, em um excelente artigo intitulado "Mercado religioso e mercado como religião", ele analisa que a teoria do mercado religioso parte da observação do pluralismo religioso e conclui que, em tal situação, "a religião se torna uma questão de escolha pessoal ou familiar e uma situação de competição entre religiões é estabelecida, subordinada à lógica da economia de mercado" (SUNG, 2014,p. 290) . Portanto, as religiões reduzidas à esfera da vida privada não podem mais cumprir a função tradicional das religiões de legitimar toda a ordem social. $\mathrm{O}$ artigo analisa a tese da subordinação da religião à lógica da economia de mercado e propõe a hipótese de que a função tradicional da religião é hoje exercida pelo próprio sistema de mercado capitalista e, portanto, pela lógica da A economia de mercado tornou-se a maneira "natural" de pensar hoje, mesmo a religião. Para isso, ele dialoga principalmente com os pensamentos de P. Berger, P. Bourdieu, M. Weber, W. Benjamin, K. Marx, F. Hinkelammert, H. Assmann e mostra como o tema da fé e da sacralização do mercado aparece. Nos discursos dos economistas. 
LIMA, F. J. (2020)

O fenômeno religioso na pós-modernidade

A religião, neste contexto da ideologia de mercado, transforma a fé em um mero espetáculo, onde o que conta é aparência e não ser. Guy Debord em seu livro "A sociedade do espetáculo" descreve muito claramente em que consiste essa sociedade:

O conceito de espetáculo unifica e explica uma grande diversidade de fenômenos aparentes. Suas diversidades e contrastes são as aparências dessa aparência socialmente organizada, que deve ser reconhecida em sua verdade geral. Considerado em seus próprios termos, o espetáculo é a afirmação da aparência e a afirmação de toda a vida humana e, portanto, social, como uma aparência simples. Mas a crítica que atinge a verdade do programa a descobre como a visível negação da vida; como uma negação da vida que se tornou visível.

Onde o mundo real é transformado em imagens simples, as imagens simples se tornam seres reais e as motivações eficientes para o comportamento hipnótico.

\section{Conclusão}

O desenvolvimento do presente trabalho possibilitou analisarmos como o fenômeno religioso na pós-modernidade possui fisionomia própria. A vivência da fé já não depende dos vínculos institucionais, o único critério é a subjetividade que, sem identificar-se com nenhuma religião, se torna um consumidor que compra ingredientes das diversas propostas religiosas e consome de acordo com seus desejos pessoais. O descrédito da razão leva um novo tipo de irracionalismo de cunho sentimentalista. Na sociedade pós-moderna assistimos à ressurreição da religião com uma pluralidade imensa de opções. Deus é visto como um poder que pode ser manipulado pelas pessoas. Deixa-se de lado a ideia de um Deus Transcendente, Onipotente e Absoluto, independente do homem, para uma pluralidade de deuses construídos à imagem e semelhança de cada pessoa de acordo com seus parâmetros individuais.

O nosso trabalho quis contribuir nesta tão necessária reflexão de como se apresenta a religião neste novo cenário da história da humanidade, que chamamos de pós-modernidade. Mas, também, somos convictos de se trata de um campo novo a ser explorado e compreendido cada vez melhor em suas inúmeras facetas.

\section{Referências}

AZEVEDO, N.S. 0 fenomeno religioso na pós-modernidade. Disponível em: < http://cienciadasreligioes.ulusofona.pt >. Acesso: 22 jun. 2020.

BINGEMER; CLARA, M. El misterio y el mundo. Madrid:San Pablo, 2017.

BAUMAN; BORDONI, C. Estado de Crisis.Titivillus, 2014.

BAUMAN. Modernidad Liquída. Diegoan, 2000.

BINGEMER; MARIA, C. El misterio y el mundo. Madrid: San Pablo, 2017.

CAVALCANTE, B; MÁRCIO. 0 conceito de pósmodernidad na sociedad atual. Disponível em: < http://www.brasilescola.com >. Acesso: 22 jun. 2020. 
LIMA, F. J. (2020)

O fenômeno religioso na pós-modernidade

CORDERO, D. Posmodernidad y nuevas formas de religión. Revista de ciencias sociales. V. 5 (2), p. 333, 2017. Disponível em: < http://dx.doi.org/10.17502/m.rcs.v5i2.137 >. Acesso: 22 jun. 2020.

DEBORD, G. La sociedad del espectáculo. Traducción de Maldeojo. Archivo Situacionista Hispano. 1998.

DAROS, W,R. El consumismo en la posmodernidad según Zygmunt Bauman./ UAP / Argentina Vol. III Edición $\mathrm{N}^{\circ}$ 12, 10 Abril 2014. California - U.S.A. Bs. As. - Argentina. Disponível em: $<$ http://www.argus-a.com.ar/publicacion/544-el-consumismo-en-la-posmodernidad-segunzygmunt-bauman.html >. Acesso: 22 jun. 2020.

DOCUMENTO DE APARECIDA. São Paulo: Paulus, 2007.

DÍAZ,A,D. Postmodernidad: El retorno de Dios. Disponível em: < https://www.monografias.com/trabajos17/retorno-dios/retorno-dios.shtml >. Acesso: 22 jun. 2020.

EVANGELII GAUDIUM,67.

GUERRERO,E. Secularismo, secularidad y secularización, p.131. Disponível em: < www. revistaespiritu.org > uploads > 2018/02 > ESP06... > . Acesso: 22 jun. 2020.

GAUDIUM ET SPES, 1965.

JUAN PABLO II. FIDES ET RATIO. 1998.

LYOTARD, F.J. La condición pós-moderna. Madrid: Cátedra, 1987.

LACOSTE; YVES,J. Diccionario critico de teologia. Madrid: Akal, 2007.

MÜLLER; GERHARD LUDWIG.G Iglesia pobre y para los pobres. Madrid: San Pablo, 2014.

MORA,A; CARLOS. Los alcances de la fe en la posmodernidad. Revista Lasallista delnvestigación. V.5(2), p.131-145, 2008. Disponível em: < https://www.redalyc.org/articulo.oa?id=69550216 >. Acesso: 22 jun. 2020.

ORTIZ; JIMÉNES, A. La fe en tiempos de incertidumbre. Madrid: San Pablo, 2018.

SUNG,J. Mercado religioso e mercado como religião. Dossiê: Religião, Mercado e Mídia. v. 12, n. 34, abr./jun. 2014. 